\title{
Unil
}

UNIL | Université de Lausanne

Unicentre

$\mathrm{CH}-1015$ Lausanne

http://serval.unil.ch

Year : 2020

\section{Oncological outcome, functional results and costs after unplanned excision of musculoskeletal soft tissue sarcoma}

\author{
Morattel Boris
}

Morattel Boris, 2020, Oncological outcome, functional results and costs after unplanned excision of musculoskeletal soft tissue sarcoma

Originally published at: Thesis, University of Lausanne

Posted at the University of Lausanne Open Archive http://serval.unil.ch

Document URN : urn:nbn:ch:serval-BIB_4561C0361F4A1

\section{Droits d'auteur}

L'Université de Lausanne attire expressément l'attention des utilisateurs sur le fait que tous les documents publiés dans l'Archive SERVAL sont protégés par le droit d'auteur, conformément à la loi fédérale sur le droit d'auteur et les droits voisins (LDA). A ce titre, il est indispensable d'obtenir le consentement préalable de l'auteur et/ou de l'éditeur avant toute utilisation d'une oeuvre ou d'une partie d'une oeuvre ne relevant pas d'une utilisation à des fins personnelles au sens de la LDA (art. 19, al. 1 lettre a). A défaut, tout contrevenant s'expose aux sanctions prévues par cette loi. Nous déclinons toute responsabilité en la matière.

\section{Copyright}

The University of Lausanne expressly draws the attention of users to the fact that all documents published in the SERVAL Archive are protected by copyright in accordance with federal law on copyright and similar rights (LDA). Accordingly it is indispensable to obtain prior consent from the author and/or publisher before any use of a work or part of a work for purposes other than personal use within the meaning of LDA (art. 19, para. 1 letter a). Failure to do so will expose offenders to the sanctions laid down by this law. We accept no liability in this respect. 


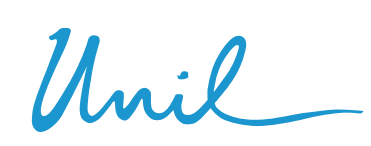

UNIL | Université de Lausanne

Faculté de biologie

et de médecine

UNIVERSITE DE LAUSANNE - FACULTE DE BIOLOGIE ET DE MEDECINE

Département de l'appareil locomoteur (DAL)

Service d'orthopédique et traumatologie (OTR)

Oncological outcome, functional results and costs after unplanned excision of musculoskeletal soft tissue sarcoma

\section{THESE}

préparée sous la direction du Docteur Stéphane Cherix (avec la co-direction du Professeur Alain Farron)

et présentée à la Faculté de biologie et de médecine de I'Université de Lausanne pour l'obtention du grade de

DOCTEUR EN MEDECINE

par

Boris Morattel

Médecin diplômé de la Confédération Suisse

Originaire de Sédeilles-Villarzel / Vaud 


\section{Imprimatur}

Vu le rapport présenté par le jury d'examen, composé de

Directeur de thèse Monsieur le Docteur Stéphane Cherix

Co-Directeur de thèse Monsieur le Professeur Alain Farron

Expert

Monsieur le Docteur Maurice Matter

Vice-Directeur de

Monsieur le Professeur John Prior

l'Ecole doctorale

la Commission MD de l'Ecole doctorale autorise l'impression de la thèse de

\section{Monsieur Boris MORATTEL}

intitulée

Oncological outcome, functional results and costs after unplanned excision of musculoskeletal soft tissue sarcoma

Lausanne, le 19 mai 2020

pour Le Doyen

de la Faculté de Biologie et de Médecine

Monsieur le Professeur John Prior Vice-Directeur de l'Ecole doctorale 


\title{
Oncological outcome, functional results and costs after unplanned excision of musculoskeletal soft tissue sarcoma
}

\author{
Boris Morattel ${ }^{\mathrm{a},}{ }^{*}$, Laurent Mustaki $^{\mathrm{a}}$, Michael Montemurro ${ }^{\mathrm{b}}$, Igor Letovanec ${ }^{\mathrm{c}}$, \\ Andre D. Durham d, Fabio Becce e, Patrick Omoumi e, Pietro G. di Summa ${ }^{\text {, }}$, \\ Maurice Matter $^{\mathrm{g}}$, Hannes A. Rüdiger ${ }^{\mathrm{h}}$, Stéphane Cherix ${ }^{\mathrm{a}}$ \\ a Service of Orthopedics and Traumatology, Lausanne University Hospital and University of Lausanne, Avenue Pierre-Decker 4, 1011, Lausanne, Switzerland \\ ${ }^{\mathrm{b}}$ Medical Oncology Department, Lausanne University Hospital and University of Lausanne, Rue du Bugnon 46, 1011, Lausanne, Switzerland \\ c Institute of Pathology, Lausanne University Hospital and University of Lausanne, Rue du Bugnon 46, 1011, Lausanne, Switzerland \\ ${ }^{\mathrm{d}}$ Radiation Oncology Department, Lausanne University Hospital and University of Lausanne, Rue du Bugnon 46, 1011, Lausanne, Switzerland \\ ${ }^{\mathrm{e}}$ Department of Diagnostic and Interventional Radiology, Lausanne University Hospital and University of Lausanne, Rue du Bugnon 46, 1011, Lausanne, \\ Switzerland \\ ${ }^{\mathrm{f}}$ Department of Plastic and Reconstructive Surgery, Lausanne University Hospital and University of Lausanne, Rue du Bugnon 46, 1011, Lausanne, \\ Switzerland \\ ${ }^{g}$ Departments of Surgery and Oncology, Lausanne University Hospital and University of Lausanne, Rue du Bugnon 46, 1011, Lausanne, Switzerland \\ h Orthopedic Department, Schulthess Clinic, Lengghalde 2, 8008, Zurich, Switzerland
}

\section{A R T I C L E I N F O}

\section{Article history:}

Accepted 17 January 2020

Available online $\mathrm{xxx}$

\section{Keywords:}

STS

Sarcoma

Functional

Costs

Unplanned

Outcome

\begin{abstract}
A B S T R A C T
Background: Treatment of soft tissue sarcomas (STS) should only be initiated once the diagnosis is fully established. Resection of tumors of unknown nature should be avoided. Nevertheless, specialized centers continue to face numbers of unplanned excisions (UPE) in STS.

Aim: To compare oncologic and functional outcomes, number of surgeries, length of hospital stay and treatment costs of UPE versus planned excision (PE) in STS.

Method: A retrospective single tertiary center study was performed on 201 patients. Survival, local and distant recurrence rates were compared between PE $(n=137)$ and UPE $(n=64)$. In a subgroup analysis of 60 patients, functional outcome (MSTS and TESS scores), and socio-economic impact (number of surgeries, length of hospital stay and treatment costs) in "functional planned excision" (fPE) group $(\mathrm{n}=30)$ and "functional unplanned excision" (fUPE) group $(\mathrm{n}=29)$ were compared.

Results: There was no significant difference in oncological outcome between PE and UPE. In the subgroup analysis, we found a non-significant difference in functional outcome. Patients in the fUPE had significantly more surgeries ( 3.5 vs. $1.4 ; \mathrm{p}<0.00001$ ) and costs of their management was $64 \%$ higher than fPE $(\mathrm{p}=0.048)$. Hospital stay was longer after fUPE but not statistically significant (18.3 days vs. 11.8 days; $\mathrm{p}=0.13)$.

Conclusion: Even though oncological and functional outcomes are comparable after PE and UPE of STS, the number of surgeries, length of hospital stay and treatment costs were higher in patients with UPE. Our data underscore the importance of specialized STS treatment centers including multidisciplinary management.
\end{abstract}

(C) 2020 Published by Elsevier Ltd.

\section{Introduction}

Musculoskeletal soft tissue tumors are frequent, often asymptomatic and therefore underdiagnosed. Benign lesions are much more

\footnotetext{
* Corresponding author.

E-mail address: morattelb@gmail.com (B. Morattel).
}

common than malignant entities. Damron et al. estimated the incidence of benign lesions at 3/1000 persons per year, while the incidence of musculoskeletal soft tissue sarcomas (STS) is estimated at $2 /$ $100^{\prime} 000$ persons per year [1]. History, symptoms or lesion location do not enable distinction between histotypes and in most cases not even between benign or malignant tumors. Extensive diagnostic work-up (e.g. MRI, CT, functional imaging and biopsy) is indicated in most cases to define an appropriate treatment strategy [2]. 
However, unplanned excisions (UPE) of STS remain frequent, occurring in up to $53 \%$ of cases [3-5]. In this setting, surgery was generally performed based on the assumption of benignity. These patients are often treated in non-specialized centers, without advanced imaging and histotype prior to surgery, as no biopsies were performed. Diagnosis is made only after surgery upon histological work-up of the specimen. As surgical margins are often insufficient (i.e. intralesional or marginal), subsequent tumor bed excision is usually necessary, with neo-adjuvant or adjuvant chemo- or radiotherapy [6-8]. Several studies have demonstrated that the oncological outcome is not different in such cases [3,9-11], whereas other authors showed that oncological results were worse after tumor bed excision [12,13] and that survival rate improved when STS were treated in a specialized center [12,13]. However, data on functional outcome in patients after UPE are currently scarce. We are aware of only one study comparing functional outcome in patients after UPE and PE of STS [9].

The purpose of this study was to assess functional and oncological outcomes as well as economic impact of STS management in patients referred to our tertiary center after UPE compared with patients who had PE in our institution.

\section{Patients and methods}

A retrospective single center study was performed in our sarcoma center. Ethical committee approval was obtained (CER-VD: 266/14).

\section{Oncological outcome}

We reviewed all patients who underwent a resection of a musculoskeletal STS or a tumor bed excision at our sarcoma center between 2000 and 2015. Oncological data were retrospectively collected from the medical files. We determined overall survival, disease-specific survival and disease-free survival (local recurrence and distant metastases).

All patients who were operated for musculoskeletal STS between 2000 and 2015 at our center were included. All patients were discussed at a multidisciplinary sarcoma board, deciding on the best (neo-) adjuvant treatment (radiotherapy, chemotherapy and ILP (Isolated Limb Perfusion)) according to the literature recommendation of the moment. Radiotherapy was given in a neoadjuvant setting for high grade STS whenever possible ( $25 \times 2 \mathrm{~Gy}=50 \mathrm{~Gy}$ in most of cases). Since 2013, radiotherapy is no longer performed systematically in low grade STS.

Patients were divided into two groups. The first group was composed of patients who had a PE at our center i.e. established sarcoma histotype and a multidisciplinary sarcoma board discussion prior to initial resection. The second group was composed of patients who needed a re-excision after UPE i.e. the diagnosis of sarcoma was not known at the initial resection.

Patients were followed up at the Orthopedic and Oncology Departments on a 3-month schedule with clinical and radiological workups.

\section{Functional outcome}

To evaluate functional outcome, we selected a subgroup of patients in the PE group ("functional" $P E=\mathrm{fPE}$ ) using the following inclusion and exclusion criteria and we compared it with a selected subgroup of patients in the UPE group ("functional" UPE = fUPE). This allowed us to have two groups with comparable epidemiological characteristics.

Patients' inclusion criteria for both "functional" subgroups were:
- to have had a surgical resection for a musculoskeletal STS in the orthopedic unit of our sarcoma center between 2000 and 2015 - functional outcome was considered definitive (minimum of 12 months since last surgery)

- consent to take part in the study

We excluded deceased patients, those unable to give a consent, missing data and patients lost to follow up. Patients with STS located in the wrist, hand, foot and ankle were excluded, due to the well-known negative impact on postoperative function of STS in those particular locations. In addition, lesions greater than $100 \mathrm{~mm}$ were excluded as they were significantly less frequently subjected to unplanned excisions than smaller lesions and would consequently induce a selection bias.

Tumor size was determined on the preoperative MRI, or, if not available (in unplanned surgeries), as reported from the pathologist's report.

Functional assessment was performed at least 12 months after the last surgery, using the patient-reported score of the Musculoskeletal Tumor Society (MSTS) [14] and the Toronto Extremity Salvage Score (TESS) [15,16].

\section{Economic impact}

Economic impact was calculated for the two functional subgroups because these two subgroup were much more statistically comparable than the overall PE and UPE groups.

We compared length of hospital stay, number of surgeries related to STS and costs. We also did multivariate analyses regarding tumor size $(<5 \mathrm{~cm}$ vs. $5-10 \mathrm{~cm}$ ) and depth (subcutaneous vs. underneath the fascia).

Data on cost of inpatient treatment were available in our institution only after 2002, so we were only able to establish cost for 29/ 31 patients in the fPE group and 25/29 in the fUPE, as they were charged to the patients' insurance according to the SwissDRG system. For the patients who had initial UPE in another center, we added the cost of outpatient excision of a benign $<5 \mathrm{~cm}$ or $>5 \mathrm{~cm}$ tumor, based on our national outpatient billing scheme.

\section{Statistical analysis}

Statistical analyses were performed using NCSS and Prism 8 software. Nonparametric pairwise comparisons of continuous variables were performed using Mann-Whitney $U$ test. Fisher's exact test or chisquared test were used for comparisons of categorical data, where appropriate. Comparison of multiple groups was performed using one-way ANOVA test. Survival was analyzed using the Kaplan-Meier method. P-values $\leq 0.05$ were considered statistically significant.

\section{Results}

\section{Oncological outcome}

Two hundred and one patients were included for this part of the study. One hundred and thirty seven out of 201 patients (68.2\%) underwent PE while in 64/201 patients (31.8\%) the diagnosis of STS was not known at the time of initial surgery (UPE).

Demographic data and tumor characteristics are detailed in Table 1.

These two groups did not differ in terms of gender, age or tumor grade, but there was a significant difference regarding localization of the tumor, with proportionally significantly more lesions of the upper extremity in the UPE group than in the PE group $(\mathrm{p}=0.0007)$. There was also a significant difference in size, with bigger tumors in the PE group $(\mathrm{p}<0.00001)$. 
Table 1

Patient epidemiologic data.

\begin{tabular}{|c|c|c|c|c|c|c|c|c|}
\hline \multirow[t]{2}{*}{ Variable } & \multirow{2}{*}{$\frac{\mathrm{PE}}{\mathrm{n}=137}$} & \multirow{2}{*}{$\begin{array}{l}\text { UPE } \\
\mathrm{n}=64\end{array}$} & \multirow[t]{2}{*}{ p-value } & \multirow{2}{*}{$\frac{\text { Total }}{\mathrm{n}=201}$} & \multirow{2}{*}{$\frac{\mathrm{fPE}}{\mathrm{n}=31}$} & \multirow{2}{*}{$\frac{\mathrm{fUPE}}{\mathrm{n}=29}$} & \multirow[t]{2}{*}{ p-value } & \multirow{2}{*}{$\frac{\text { Total }}{\mathrm{n}=60}$} \\
\hline & & & & & & & & \\
\hline Gender & & & 0.44 & & & & 0.12 & \\
\hline Male & 79 & 35 & & 114 & 16 & 21 & & 37 \\
\hline Female & 58 & 29 & & 87 & 15 & 8 & & 23 \\
\hline Age & $55.9(12-93)$ & $52.2(12-94)$ & 0.11 & $54.7(12-94)$ & 50 & 54 & 0.18 & (med 52) \\
\hline Tumor site & & & 0.0007 & & & & 0.102 & \\
\hline Upper extremity & 15 & 15 & & 30 & 6 & 12 & & 18 \\
\hline Shoulder/arm & 11 & 4 & & 15 & 5 & 4 & & 9 \\
\hline Elbow/forearm/hand & 4 & 11 & & 15 & 1 & 8 & & 9 \\
\hline Lower Extremity & 120 & 45 & & 165 & 25 & 17 & & 42 \\
\hline Pelvic ring/buttock & 14 & 4 & & 18 & 4 & 4 & & 8 \\
\hline Thigh & 79 & 22 & & 101 & 15 & 8 & & 23 \\
\hline Knee/lower leg & 22 & 14 & & 36 & 6 & 5 & & 11 \\
\hline Ankle/foot & 5 & 5 & & 10 & 0 & 0 & & 0 \\
\hline Back & 2 & 4 & & 6 & 0 & 0 & & 0 \\
\hline Depth & & & $<0.00001$ & & & & 0.02 & \\
\hline Superficial & 26 & 36 & & 62 & 9 & 18 & & 27 \\
\hline Deep & 111 & 28 & & 139 & 22 & 11 & & 33 \\
\hline Histology & & & 0.06 & & & & 0.002 & \\
\hline Unclassified sarcoma & 41 & 16 & & 57 & 7 & 6 & & 13 \\
\hline Lipomatous tumors & 40 & 11 & & 51 & 11 & 3 & & 14 \\
\hline WDLPS/ALT* & 23 & 6 & & 29 & 9 & 2 & & 11 \\
\hline Grade 2 or 3 & 17 & 5 & & 22 & 2 & 1 & & 3 \\
\hline Myxofibrosarcoma & 11 & 12 & & 23 & 2 & 10 & & 12 \\
\hline Leiomyosarcoma & 8 & 7 & & 15 & 0 & 5 & & 5 \\
\hline Synovialosarcoma & 12 & 3 & & 15 & 4 & 0 & & 4 \\
\hline Fibromyxoid sarcoma & 8 & 1 & & 9 & 3 & 0 & & 3 \\
\hline ES chondrosarcoma ${ }^{* *}$ & 3 & 1 & & 4 & 2 & 0 & & 2 \\
\hline MPNST $^{* * *}$ & 2 & 2 & & 4 & 0 & 2 & & 2 \\
\hline Epithelioid sarcoma & 1 & 3 & & 4 & 1 & 1 & & 2 \\
\hline Other & 11 & 8 & & 19 & 1 & 2 & & 3 \\
\hline Grade $\left(\right.$ FNCLCC $\left.^{* * *}\right)$ & & & 0.98 & & & & 0.42 & \\
\hline Low & $34(24.8 \%)$ & $15(23.4 \%)$ & & $49(24.4 \%)$ & $12(38.7 \%)$ & $9(31 \%)$ & & $21(35 \%)$ \\
\hline Intermediate & $53(38.7 \%)$ & $25(39.1 \%)$ & & $78(38.8 \%)$ & $13(41.9 \%)$ & $10(34.5 \%)$ & & $23(38.3 \%)$ \\
\hline High & $50(36.5 \%)$ & $24(37.5 \%)$ & & $74(36.8 \%)$ & $6(19.4 \%)$ & $10(34.5 \%)$ & & $16(26.7 \%)$ \\
\hline Size & & & $<0.00001$ & & & & 0.12 & \\
\hline$<50 \mathrm{~mm}$ & $33(24,1 \%)$ & $39(60.9 \%)$ & & $72(35.8 \%)$ & $15(48.3 \%)$ & $20(69 \%)$ & & $35(58.3 \%)$ \\
\hline $50-100 \mathrm{~mm}$ & $47(34,3 \%$ & $14(21.9 \%)$ & & $61(30.3 \%)$ & $16(51.6 \%)$ & $9(31 \%)$ & & $25(41.7 \%)$ \\
\hline$>100 \mathrm{~mm}$ & $57(41.6 \%)$ & $11(17.2 \%)$ & & $68(33.8 \%)$ & 0 & 0 & & 0 \\
\hline Mean size (mm) & 92 & 56 & & $(\operatorname{med} 81)$ & 46 & 42 & & (med 44) \\
\hline Mean follow up (month) & 89 & 99 & & 92 & 77 & 79 & & 78 \\
\hline
\end{tabular}

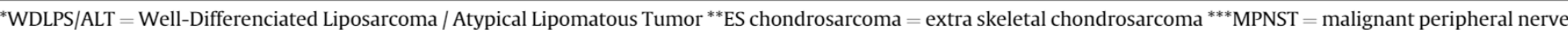
sheath tumor ${ }^{* * * *}$ FNCLCC $=$ Fédération Nationale des Centres de lutte Contre le Cancer.

With a median follow-up of 92 months, overall 48 patients (24\%) died, 37 due to the STS (disease-specific death rate $=18.4 \%$ ), 153 were alive (76\%), and 120 (59.7\%) were alive and disease-free. Fiveand ten-year survival rates were $86.1 \%$ and $84.1 \%$, respectively. Fifteen patients (7.5\%) had local recurrence, of whom five were alive at time of last follow-up. Median time to local recurrence was 34 months. Fifty-nine patients (29.3\%) had distant recurrence, of whom 28 were alive at time of follow-up. Median time to distant recurrence was 24 months. Oncological outcome for the whole cohort and the different subgroups are presented in Table 2 and in Figs. $1-3$.

\section{Functional results}

Eighty-nine out of 201 patients (44.3\%) met the inclusion criteria for functional analysis. Four had moved abroad, we were unable to contact 22, and 3 refused to take part in the study. Sixty patients were included and completed the patient reported outcome measures. Median follow-up was 78 months (range: 12-187 months). The cohort was divided into two subgroups consisting of $31 / 60$ patients $(51.7 \%)$ who had planned excision (fPE) and 29/60 patients (48.3\%) who had an unplanned excision (fUPE). The demographic data of these subgroups are detailed in Table 1 and were statistically comparable in term of gender $(p=0.12)$, age $(p=0.18)$, tumor site $(p=0.102)$, grade $(p=0.42)$ and size $(\mathrm{p}=0.12)$. There was more superficial (localization above the fascia) in the fUPE group than in the fPE group ( $p=0.02)$.

There was no statistical difference between fPE and fUPE regarding oncological (Table 2 ) and functional outcomes (Table 3 ). In multivariate analysis, we did not find any significant correlation between grade and functional results, but we found a trend with superficial STS having worse functional outcome in the fUPE subgroup (Table 4). On multivariate analysis, the addition of radiotherapy did not significantly influence functional results $(\mathrm{p}=0.82$ for MSTS and $\mathrm{p}=0.62$ for TESS).

\section{Economic impact}

Patients in the fUPE group had on average two more surgeries than those in the fPE group $(\mathrm{p}<0.00001)$ and five more days of 
Table 2

Oncological outcome.

\begin{tabular}{|c|c|c|c|c|c|c|c|c|}
\hline \multirow[t]{2}{*}{ Variable } & \multirow{2}{*}{$\frac{P E}{n=137}$} & \multirow{2}{*}{$\begin{array}{l}\text { UPE } \\
\mathrm{n}=64\end{array}$} & \multirow[t]{2}{*}{ p-value } & \multirow[t]{2}{*}{ Total } & \multirow{2}{*}{$\frac{\mathrm{fPE}}{\mathrm{n}=31}$} & \multirow{2}{*}{$\frac{\text { fUPE }}{n=29}$} & \multirow[t]{2}{*}{ p-value } & \multirow{2}{*}{$\frac{\text { Total }}{\mathrm{n}=60}$} \\
\hline & & & & & & & & \\
\hline \multicolumn{9}{|l|}{ Survival status } \\
\hline Alive & 103 & 50 & & $153(76.1 \%)$ & 31 & 29 & 1 & 60 \\
\hline Deceased of sarcoma & $25(24 \%)$ & $12(19 \%)$ & 1 & $37(18.4 \%)$ & & & & \\
\hline Total Deceased & 34 & 14 & 0.72 & $48(23.9 \%)$ & & & & \\
\hline Grade 1 deceased of sarcoma & & & & 0 & & & & \\
\hline Grade 2 deceased of sarcoma & & & & 9 & & & & \\
\hline Grade 3 deceased of sarcoma & & & & 25 & & & & \\
\hline Local recurrence & & & 0.25 & & & & 1 & \\
\hline No & 129 & 57 & & 186 & 30 & 28 & & 58 \\
\hline Yes & $8(6 \%)$ & $7(11 \%)$ & & $15(7.5 \%)$ & 1 & 1 & & 2 \\
\hline Residue after tumour bed excision & & $20(31 \%)$ & & & & 16 & & \\
\hline Distant recurrence (metastasis) & & & 0.25 & & & & 1 & \\
\hline No & 93 & 49 & & 142 & 26 & 25 & & 51 \\
\hline Yes & $44(31.7 \%)$ & 15 (23.4\%) & & $59(29.3 \%)$ & 5 & 4 & & 9 \\
\hline
\end{tabular}

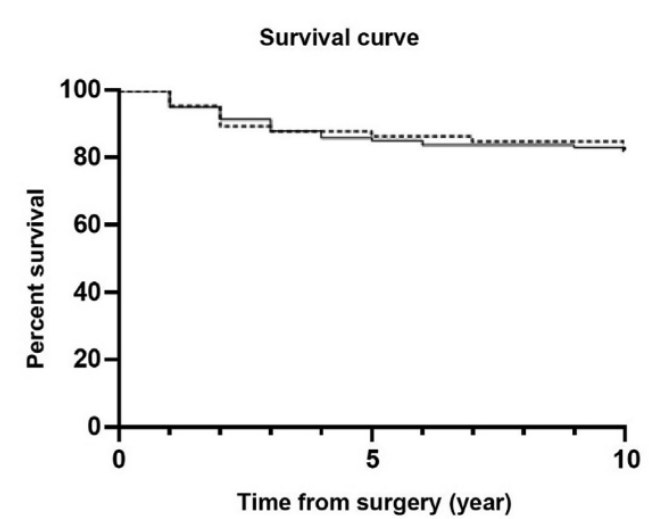

Fig. 1. 10 year survival.

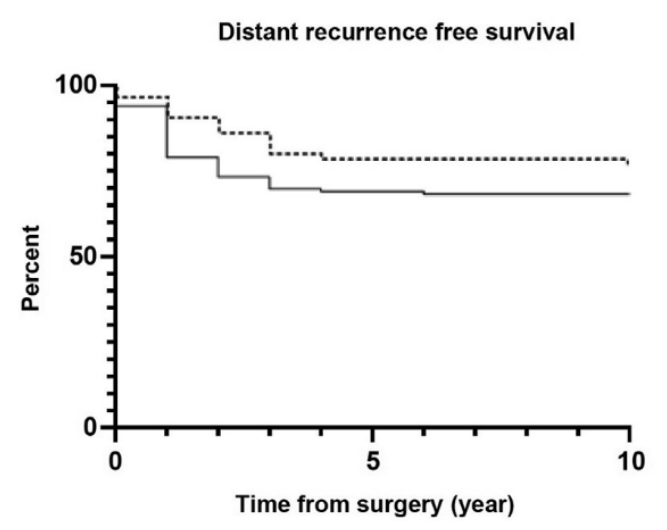

- PE

-... UPE

$n=201$

Fig. 2. 10 year distant recurrence free survival.

hospitalization $(\mathrm{p}=0.18)$.

Patients with high grade STS had significantly more surgeries than those with low grade (mean of 2.2 surgeries in high grade versus 1 in low grade, $\mathrm{p}=0.03$ ) in the $\mathrm{PPE}$, but there was no correlation between grade and the number of surgeries in the fUPE (3.2 surgeries in high grade versus 3.8 surgeries in low grade, $\mathrm{p}=0.8$ ). We did not find any significant correlation between grade and functional results or length of hospital stay.

In the multivariate analysis, we found a significantly higher number of surgical procedures in every fUPE subgroup $(<5 \mathrm{~cm}$,

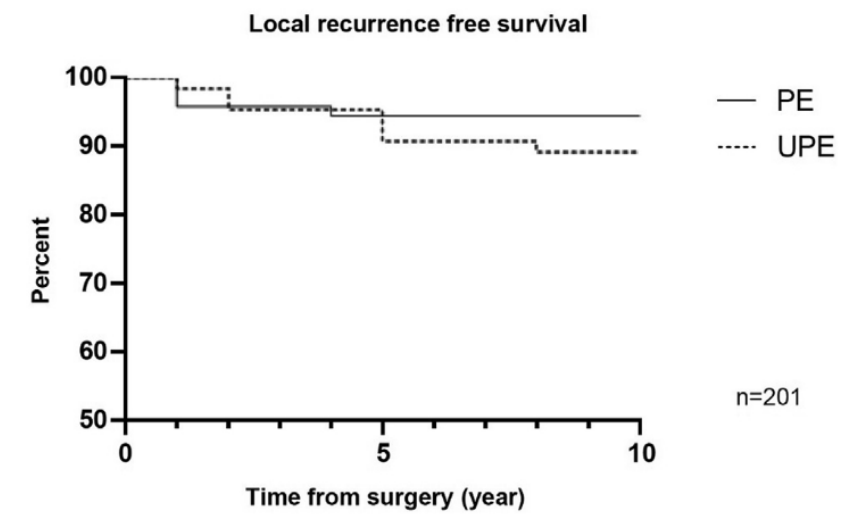

Fig. 3. 10 year local recurrence free survival.

Table 3

Functional results.

\begin{tabular}{|c|c|c|c|}
\hline \multirow[t]{2}{*}{ Variable } & \multirow{2}{*}{$\frac{\mathrm{fPE}}{\mathrm{n}=31}$} & \multirow{2}{*}{$\frac{\text { fUPE }}{n=29}$} & \multirow[t]{2}{*}{ p-value } \\
\hline & & & \\
\hline MSTS score & 25,4 & 24,2 & 0,99 \\
\hline TESS & 92.8 & 87.7 & 0.90 \\
\hline Number of surgical procedures & 1,4 & 3,5 & $<0.00001$ \\
\hline Time of hospital stay (days) & 12,8 & 18.3 & 0,13 \\
\hline Cost $(€)$ & $18^{\prime} 101$ & $28^{\prime} 185$ & 0.0477 \\
\hline \multicolumn{4}{|l|}{ Radiation therapy } \\
\hline Neo-Adjuvant & 20 & 21 & \\
\hline Adjuvant & 3 & 1 & 0.61 \\
\hline \multicolumn{4}{|l|}{ Chemotherapy } \\
\hline Neo-Adjuvant & 3 & 1 & \\
\hline Adjuvant & 1 & 1 & 0.74 \\
\hline ILP (Isolated Limb Perfusion) & 1 & 0 & 1 \\
\hline
\end{tabular}

5-10 cm, superficial and deep), but no statistically significant difference in functional results or length of hospital stay (Table 4). We observed a trend in superficial STS in the fUPE doing worse regarding length of hospital stay and number of surgeries compared to deep lesions. All these data are described in Table 4.

When we compared deep and superficial tumors in the fUPE subgroup, we observed a significantly higher risk of secondary surgical wound closures by skin graft or flap in the superficial fUPE subgroup ( $\mathrm{p}=0.03$ ). Twelve out of 18 patients who underwent tumor bed excision for a superficial STS needed skin graft or flap coverage whereas only 2 out of 11 patients (18\%) secondarily 
Table 4

Functional multivariate analysis.

\begin{tabular}{|c|c|c|c|c|c|c|}
\hline & \multicolumn{3}{|c|}{ Superficial } & \multicolumn{3}{|l|}{ Deep } \\
\hline & fPE & fUPE & $\begin{array}{l}\mathrm{p}- \\
\text { value }\end{array}$ & fPE & fUPE & $\begin{array}{l}\mathrm{p}- \\
\text { value }\end{array}$ \\
\hline Number of patients & 9 & 18 & & 21 & 11 & \\
\hline Mean age & 50 & 42 & 0.13 & 51 & 51 & 1 \\
\hline Average size of tumor (mm) & 39 & 37 & 0.10 & 38 & 49 & 0.63 \\
\hline MSTS score & 27.6 & 23.8 & 0.33 & 24.6 & 24.8 & 0.51 \\
\hline TESS & 94.2 & 88.1 & 0.37 & 92.5 & 87.2 & 0.57 \\
\hline Time of hospital stay & 9 & 17.5 & 0.16 & 14.4 & 19.7 & 0.56 \\
\hline Surgical procedures & 1,2 & 3.2 & 0.0002 & 1,5 & 3.9 & 0.0005 \\
\hline \multirow[t]{3}{*}{$\begin{array}{l}\text { Tumor residue after Tumor bed } \\
\text { excision }\end{array}$} & & $\begin{array}{l}9 \\
(50 \%)\end{array}$ & & & $\begin{array}{l}6 \\
(54 \%)\end{array}$ & \\
\hline & \multicolumn{3}{|c|}{ Tumor $<5 \mathrm{~cm}$} & \multicolumn{3}{|c|}{ Tumor $5-10 \mathrm{~cm}$} \\
\hline & fPE & fUPE & $\begin{array}{l}\mathrm{p}- \\
\text { value }\end{array}$ & fPE & fUPE & $\begin{array}{l}\mathrm{p}- \\
\text { value }\end{array}$ \\
\hline Number of patients & 14 & 20 & & 16 & 9 & \\
\hline Mean age & 45 & 54 & 0.10 & 54 & 55 & 0.71 \\
\hline Average size of tumor (mm) & 30 & 28 & 0.08 & 56 & 63 & 0.56 \\
\hline MSTS score & 24 & 22.8 & 0.98 & 26.9 & 27.3 & 0.63 \\
\hline TESS & 90.3 & 82.6 & 1 & 95.4 & 99.1 & 0.41 \\
\hline Time of hospital stay & 15.8 & 19.3 & 0.81 & 10.3 & 16.3 & 0.08 \\
\hline Surgical procedures & 1.8 & 3.6 & 0.001 & 1.1 & 3.1 & 0.0001 \\
\hline $\begin{array}{l}\text { Tumor residue after Tumor bed } \\
\text { excision }\end{array}$ & & $\begin{array}{l}9 \\
(45 \%)\end{array}$ & & & $\begin{array}{l}6 \\
(66 \%)\end{array}$ & \\
\hline
\end{tabular}

needed a flap for wound coverage in the deep fUPE subgroup.

Average cost of management of a patient in the fPE group was $€$ $18^{\prime} 101$ whereas the management cost of a patient in the fUPE group was $€ 28^{\prime} 185$ ( $\left.p=0.048\right)$, representing a $64 \%$ higher cost for fUPE.

\section{Discussion}

In our series, the proportion of UPE in STS patients was 31.8\%. This is in line with the literature, with some studies reporting up to $53 \%$ of UE [3-5]. In their recent review, Grimer et al. [17] found rates between $18 \%$ and $53 \%$, with an average of $33 \%$. Interestingly, like in other studies, it remained stable throughout the analyzed period. Surgeons' raise of awareness to this problematic is the keypoint to decreasing this rate. Nandra et al. created an aidemémoire, "larger than a golfball and growing", to trigger referral to tertiary tumour units [18]. To our knowledge, they have not yet published data on the efficiency of this prevention strategy.

The first part of our work consisted in comparing the oncological outcome between patients who underwent PE in our center and patients who had prior UPE in a non-specialized center, and were then referred to us for salvage treatment. All our patients were treated surgically: our study did not take into consideration patients with advanced disease and palliative treatments. Epidemiologic data for age, gender, localization, depth and histologic subtypes are comparable with the literature [19-21].

The local recurrence rate for our whole cohort was $7 \%$ at time of follow up (mean 92 months), the distant recurrence rate was $26.9 \%$, and the disease-specific survival rate was 17\%. In 1996, Pisters et al. in a cohort of 1041 surgically treated musculoskeletal STS patients, had similar results, with $17 \%, 22 \%$ and $24 \%$ respectively at 4 years [20]. More recent studies showed a local recurrence rate around $4.1 \%-10 \%$ [22-25]. A major factor affecting outcomes is the inclusion of atypical lipomatous tumors/well differentiated liposarcoma (ALT/WDLPS) in our series, as they were considered as "true" sarcomas until 2012, when the WHO declassified them into tumors of intermediate aggressiveness. On the contrary, NCCN guidelines of 2005 did not separate ALT/WDLPS from other low grade STS [26]. It is difficult to know if ALT/WDLPS were excluded or even considered in most of the literature on STS, even in more recent publications [10], for it is generally not specified. In total, 29 ALT/WDLPS were included, 6 in the UPE and 23 in the PE groups. In our center, the last neoadjuvant radiotherapy for a ALT/WDLPS was performed in 2013, and the vast majority received complementary therapy (18 neoadjuvant and one adjuvant radiotherapy, one isolated limb perfusion). In the end, one patient presented distant metastases, and from the two ALT/WDLPS of the UPE group who had residue at tumor bed excision, one had a local recurrence. Since 2013, we do not automatically re-excise ALT/WDLPS after R1 primary excision. We generally follow them with local imaging for $2-5$ years on caseby-case discussion.

In our study, the majority of patients with UPE had subcutaneous ( $p<0.00001)$ and elbow/forearm STS $(p=0.0007)$ compared with patients with PE. Alamanda et al. also found an increased rate of unplanned excisions in superficial tumors and in upper extremity [27]. Forearm lumps are more frequently removed by plastic or hand surgeons than in other parts of the body: in our series, there were 9 cases of unplanned excision in the forearm, 7 of them $(78 \%)$ by plastic surgeons in private practice, one by a general surgeon and one by an orthopaedic surgeon. Sensitization of plastic surgeons during continuing education and training is certainly a key, as they are on the front line for treating lumps in the upper extremities in their daily practice. Generally speaking, orthopaedic and general surgeons seem to be more at risk of performing an unplanned excision of STS, all locations included [28].

We did not find any significant difference in size or histotype, but observed a trend towards more frequent UPE of myxofibrosarcoma in our series, although the most frequent histotype was unclassified pleomorphic sarcoma. There is no evidence in the literature of an association of unplanned excision with a specific histotype: some authors found more frequent UPE of synovial sarcoma [29,30], liposarcomas [10,27,31], unclassified pleomorphic sarcoma [32] or myxofibrosarcoma [10].

Some studies showed that local recurrence rate after UPE was doubled [21]. At time of follow up (mean 92 months), we also found a two times higher local recurrence rate in the UPE group compared with the PE group ( $12.5 \%$ versus $6.2 \% \mathrm{p}=0.25$ ), although it was not statistically significant, due to the small number of patients. Chandrasekar et al. Potter et al. and Noria et al. also found local recurrence rates after unplanned excision to be significantly higher [33-35].

Our distant recurrence rates were respectively $31.7 \%$ (PE) and $23.4 \%$ (UPE) ( $p=0.25$ ) and the specific mortality rates were $16 \%$ $(\mathrm{PE})$ and $19 \%(\mathrm{UPE})(\mathrm{p}=0.69)$. In their study, Fiore et al. and Alamanda et al. had comparable long-term oncological outcomes when comparing PE and UPE [3,11]. On the other hand, Derbel et al. showed in a prospective study of 472 localized STS of the musculoskeletal system that treatment in a specialized center reduced disease specific mortality by $66 \%$ [13].

In our cohort of 201 patients, as in Fiore et al. and Alamanda et al., we observed a significant difference in tumor size between the two groups: $56 \mathrm{~mm} \pm$ in the UPE group versus $92 \mathrm{~mm}$ in the PE group ( $\mathrm{p}<0.00001)$. For this reason, in the second part of the study, we aimed to compare two epidemiologically similar groups. Our cohort, even if small in size, also suggests that oncological outcomes are comparable when considering local or distant recurrence rates, whatever the initial surgery (planned or unplanned).

STS are rare and can emerge in different ways, there are more than fifty different types, they are ubiquitous and their aggressiveness is highly variable. Diagnosis itself can be challenging [36]. This heterogeneity makes it difficult to analyze the functional results after their management [37]. However, the principles of sarcoma management are quite constant, whatever the type and location, i.e. wide excision, with clear margins and limb 
preservation whenever possible. Morii et al. showed that unplanned excision had no significant impact on functional results [9]. It is difficult to measure the emotional impact of secondary medical care in a specialized center by a multidisciplinary team after initial so-called whoops surgery by a "non-specialist" surgeon. To our knowledge, there is no specific score to estimate it. In their recent review article on psychological wellbeing of sarcoma patients, Storey et al. found 82 publications [38]. The main studied parameter was quality of life, but it was not possible for the authors to conclude on the psychological impact of sarcoma. The importance of being treated in a specialized center, especially after accidental "inadequate" excision of a STS may have a favorable influence on the patient when fulfilling functional score forms. We agree with Storey et al. that there is certainly a need for the inclusion of relevant psychological measurements in functional analysis of oncological treatment. They might support Morii et al. who concluded that these patients had a better emotional acceptance. Finally, esthetic results and acceptance remain largely unexplored and should be included in future patient reported outcomes.

The most important finding of our study was that patients who underwent UPE need significantly more procedures (with an average of two more surgical interventions) than PE patients, regardless of depth and size of the tumor. This is due to the fact that a tumor bed excision in this situation may involve a large cutaneous excision requiring secondary graft or flap coverage. Our study also showed that length of hospital stay was longer in case of UPE. However, our cohort was too small to reach statistical significance and further studies are needed to confirm this trend. This difference appeared to be more present for superficial tumors, where the skin defect is often more important.

The average cost of hospital care for a patient who had UPE was significantly higher than planned excision (64\% more). To our knowledge, this has never been precisely measured before for STS of the extremities. Barrientos-Ruiz et al. showed that referring patients to a sarcoma center after biopsy had higher costs than before the biopsy [39], but their study was not clear about the what kind of biopsy was done in the non-reference center, i.e. if it was excisional biopsy, unplanned resection, surgical biopsy or percutaneous core-needle biopsy.

Recently, a large prospective study by Decanter et al. [40] demonstrated no metastatic free survival and overall survival benefit for systematic re-excision as compared to a "wait and see" approach after R0 and R1UPE. As systematic re-excision leads to more interventions, complex reconstructions and higher cost, as demonstrated by our study, a "wait and see" attitude might be considered in some cases, in particular in superficial low to intermediate tumors or some unfavorable deep-seated tumors. It is worse mentioning that even though the amputation rate did not raise in their series (with $23.3 \%$ of truncal sarcomas!), the functional impact of re-excision at the time of local recurrence as compared to immediately after UPE was not analyzed in their study. Neither was the cost of a "wait and see" approach determined. In our series, this strategy would have lead to a significantly higher rate of local recurrence, considering that $31 \%$ had tumor residue at re-excision. Hence, it may be premature to change our guidelines, but there is obviously space for considering no re-excision in some cases of UPE: this needs to be determined in a "case-by-case" discussion in a multidisciplinary sarcoma board.

\section{Conclusion}

Our study did not demonstrate any significant oncological or functional difference, regardless of the initial surgical management of STS of the musculoskeletal system in a reference center or by a non-specialist surgeon. However, we found a significantly higher number of surgical procedures and longer hospital stay after unplanned excision of STS, resulting in a $64 \%$ higher cost as compared to planned excision in a reference center.

The most common location for unplanned excision appears to be in the forearm. Nearly one-third $(31.8 \%)$ of patients with musculoskeletal STS are referred to a specialized center after unplanned excision and we believe that providing ongoing education of non-specialists is crucial to prevent accidental excision of STS. Every patient with a suspicion of STS should be referred as soon as possible for an adequate management of the disease, as the ESMO guidelines suggests [41], in order to reduce the costs of management and to prevent additional surgeries.

\section{References}

[1] Damron TA, et al. Soft-tissue lumps and bumps. J Bone Jt Surg Am Vo 2003;85a(6): $1142-55$.

[2] Bannasch $\mathrm{H}$, et al. The diagnosis and treatment of soft tissue sarcomas of the limbs. Dtsch Arztebl Int 2011;108(3):32-8.

[3] Fiore M, et al. Prognostic effect of re-excision in adult soft tissue sarcoma of the extremity. Ann Surg Oncol 2006;13(1):110-7.

[4] Pretell-Mazzini J, et al. Unplanned excision of soft-tissue sarcomas current concepts for management and prognosis. J Bone Jt Surg Am Vol 2015;97a(7): 597-603.

[5] Kang S, Kim HS, Han I. Unplanned excision of extremity soft tissue sarcoma in Korea: a nationwide study based on a claims registry. PloS One 2015;10(8): e0134354.

[6] Collin C, et al. Localized operable soft-tissue sarcoma of the upper extremity presentation, management, and factors affecting local recurrence in 108 patients. Ann Surg 1987;205(4):331-9.

[7] Davis AM, et al. The impact of residual disease on local recurrence in patients treated by initial unplanned resection for soft tissue sarcoma of the extremity. J Surg Oncol 1997;66(2):81-7.

[8] Koulaxouzidis G, et al. Is revisional surgery mandatory when an unexpected sarcoma diagnosis is made following primary surgery? World J Surg Oncol $2015 ; 13$.

[9] Morii T, et al. Unplanned resection of a soft tissue sarcoma: clinical characteristics and impact on oncological and functional outcomes. J Orthop Sci 2015;20(2):373-9.

[10] Smolle MA, et al. The prognostic impact of unplanned excisions in a cohort of 728 soft tissue sarcoma patients: a multicentre study. Ann Surg Oncol 2017:24(6):1596-605.

[11] Alamanda VK, et al. Primary excision compared with re-excision of extremity soft tissue sarcomas-is anything new? J Surg Oncol 2012;105(7):662-7.

[12] Traub F, et al. Influence of unplanned excisions on the outcomes of patients with stage III extremity soft-tissue sarcoma. Cancer 2018;124(19):3868-75.

[13] Derbel O, et al. Survival impact of centralization and clinical guidelines for soft tissue sarcoma (A prospective and exhaustive population-based cohort). Plos One 2017:12(2):e0158406.

[14] Enneking WF, et al. A system for the functional evaluation of reconstructive procedures after surgical treatment of tumors of the musculoskeletal system. Clin Orthop Relat Res 1993;(286):241-6.

[15] Davis AM, et al. Development of a measure of physical function for patients with bone and soft tissue sarcoma. Qual Life Res 1996;5(5):508-16.

[16] Clayer M, et al. The toronto extremity salvage score in unoperated controls: an age, gender, and country comparison. Sarcoma; 2012. p. 717213. 2012.

[17] Grimer R, Parry M, James S. Inadvertent excision of malignant soft tissue tumours. EFORT Open Rev 2019;4(6):321-9.

[18] Nandra R, Forsberg J, Grimer R. If your lump is bigger than a golf ball and growing, think Sarcoma. Eur J Surg Oncol 2015;41(10):1400-5.

[19] Brennan MF, Antonescu CR, Maki RG. Management of soft tissue sarcoma. New York: Springer. xv; 2013. p. 380.

[20] Pisters PW, et al. Analysis of prognostic factors in 1,041 patients with localized soft tissue sarcomas of the extremities. J Clin Oncol 1996;14(5):1679-89.

[21] Ipach I, et al. Oncological outcome and prognostic factors in the therapy of soft tissue sarcoma of the extremities. Orthop Rev 2012;4(4):e34.

[22] Novais EN, et al. Do surgical margin and local recurrence influence survival in soft tissue sarcomas? Clin Orthop Relat Res 2010;468(11):3003-11.

[23] Guerrero WM, Deneve JL. Local recurrence of extremity soft tissue sarcoma. Surg Clin 2016:96(5):1157-74.

[24] Gundle KR, et al. Analysis of margin classification systems for assessing the risk of local recurrence after soft tissue sarcoma resection. J Clin Oncol 2018;36(7):704-9.

[25] Muller DA, et al. Combining limb-sparing surgery with radiation therapy in high-grade soft tissue sarcoma of extremities - is it effective? Eur J Surg Oncol 2016;42(7):1057-63.

[26] Demetri GD, et al. Soft tissue sarcoma clinical practice guidelines in oncology. J Natl Compr Canc Netw 2005;3(2):158-94.

[27] Alamanda VK, et al. Incomplete excisions of extremity soft tissue sarcomas are unaffected by insurance status or distance from a sarcoma center. J Surg Oncol 
2013;108(7):477-80.

[28] Venkatesan M, et al. Inadvertent surgical resection of soft tissue sarcomas. Eur J Surg Oncol 2012;38(4):346-51.

[29] Alamanda VK, et al. The financial burden of reexcising incompletely excised soft tissue sarcomas: a cost analysis. Ann Surg Oncol 2013;20(9):2808-14.

[30] Siegel H], et al. Unplanned surgical excision of extremity soft tissue sarcomas: patient profile and referral patterns. J Surg Orthop Adv 2009;18(2):93-8.

[31] Cahlon O, et al. Long term outcomes in extremity soft tissue sarcoma (STS) after a pathologically negative re-resection and without radiotherapy (RT). Int J Radiat Oncol Biol Phys 2007;69(3). S94-S94.

[32] Kang S, et al. Unplanned excision of soft tissue sarcoma: the impact of the referring hospital. Surg Oncol 2013;22(2):e17-22.

[33] Chandrasekar CR, et al. The effect of an unplanned excision of a soft-tissue sarcoma on prognosis. J Bone Jt Surg Br 2008;90b(2):203-8.

[34] Potter BK, et al. Local recurrence of disease after unplanned excisions of highgrade soft tissue sarcomas. Clin Orthop Relat Res 2008;466(12):3093-100.

[35] Noria S, et al. Residual disease following unplanned excision of a soft-tissue sarcoma of an extremity. J Bone Jt Surg Am Vol 1996;78a(5):650-5.
[36] Perrier L, et al. The cost-saving effect of centralized histological reviews with soft tissue and visceral sarcomas, GIST, and desmoid tumors: the experiences of the pathologists of the French Sarcoma Group. PloS One 2018;13(4); e0193330.

[37] Davis AM. Functional outcome in extremity soft tissue sarcoma. Semin Radiat Oncol 1999;9(4):360-8.

[38] Storey L, et al. A critical review of the impact of sarcoma on psychosocial wellbeing. Sarcoma; 2019. p. 9730867. 2019.

[39] Barrientos-Ruiz I, Serrano-Montilla J, Ortiz-Cruz E]. [Cost analysis of the diagnosis and treatment of soft tissue sarcomas in reference centres]. Rev Española Cirugía Ortopédica Traumatol 2012;56(5):374-7.

[40] Decanter G, et al. Watch and wait approach for Re-excision after unplanned yet macroscopically complete excision of extremity and superficial truncal soft tissue sarcoma is safe and does not affect metastatic risk or amputation rate. Ann Surg Oncol 2019;26(11):3526-34.

[41] Rosanova M, et al. Sleep-like cortical OFF-periods disrupt causality and complexity in the brain of unresponsive wakefulness syndrome patients. Nat Commun 2018;9(1):4427. 